\title{
Simulation model of quarter milk flowrates to estimate quarter and cow milking duration and automated milking system's box duration
}

\author{
P. Silva Boloña, ${ }^{1,2 *} \odot$ J. Upton, ${ }^{1} \oplus$ V. Cabrera, ${ }^{2} \odot$ T. Erker, ${ }^{3} \odot$ and D. J. Reinemann ${ }^{4} \odot \odot$ \\ ${ }_{1}^{1}$ Animal and Grassland Research and Innovation Centre, Teagasc Moorepark Fermoy, Co. Cork, Ireland P61 C996 \\ ${ }^{2}$ Department of Animal and Dairy Sciences, University of Wisconsin-Madison, Madison, 53706 \\ ${ }^{3}$ Department of Statistics, University of Wisconsin-Madison, Madison, 53706 \\ ${ }^{4}$ Biological Systems Engineering Department, University of Wisconsin-Madison, Madison, 53706
}

\section{ABSTRACT}

The aims of this research were (1) to develop a model to simulate a herd of cows and quarter milk flowrates for a milking and derive quarter and udder milking durations and box duration (i.e., the time a cow spends inside the robot) for a group of cows milked with an automatic milking system (AMS); (2) to validate the simulation by comparing the model outcomes with empirical data from a commercial AMS dairy farm; and (3) to apply teatcup removal settings to the simulation to predict their effect on quarter and cow milking duration and box duration in an AMS. For model development, a data set from an AMS farm with 32 robots milking over 1,500 cows was used to fit the parameters to the variables days in milk, parity, and milking interval, which were subsequently used to create a herd of cows. A second data set from 2019 from an AMS farm with 1 robot milking 60 cows that contained quarter milk flowrates (at 2-s intervals) was used to extract the parameters necessary to simulate quarter milk flowrates for a milking. We simulated a herd of cows, and each was assigned a parity, days in milk, milking interval, and milk production rate. We also simulated milk flowrates every $1 \mathrm{~s}$ for each quarter of each cow. We estimated quarter milking duration as the total time that flowrate was greater than $0.1 \mathrm{~kg} / \mathrm{min}$ after a minimum of 1 min of milk flow. We incorporated a randomly sampled attachment time for each quarter and calculated cow milking duration as the time from the first quarter attached to the last quarter detached. We included a randomly sampled preparation time which, added to cow milking duration, represented box duration. For simulation application, we tested the effect of quarter teatcup removal settings on quarter and cow milking duration. The settings were based on absolute flowrate $(0.2,0.4$, and $0.6 \mathrm{~kg} / \mathrm{min})$ or a percentage of

Received March 16, 2021.

Accepted December 22, 2021.

*Corresponding author: pablo.silvabolona@teagasc.ie the quarter's 30-s rolling average milk flowrate $(20,30$, and $50 \%$ ). We simulated over 84,000 quarter milkings and found that quarter milking duration (average 212 s) had a mean absolute percent error (MAPE) of 7.5\% when compared with actual data. Simulated cow milking duration (average $415 \mathrm{~s}$ ) had a MAPE of $8 \%$, and box duration (average $510 \mathrm{~s}$ ) had a MAPE of $12 \%$. From simulation application, we determined that quarter milking duration and box duration were reduced by $19 \%$ (209 vs. 170 s) and $6.5 \%$ (512 vs. 479 s), respectively, when increasing the teatcup removal flowrate from 0.2 to $0.6 \mathrm{~kg} / \mathrm{min}$. Quarter milking duration and box duration were $7 \%$ (259 vs. 241 s) and $3 \%$ (590 vs. $573 \mathrm{~s}$ ) longer respectively by using a teatcup removal setting of $20 \%$ of the quarter's rolling average milk flowrate, compared with $30 \%$. Both results agree with previous research. This simulation model is useful for predicting quarter and cow milking and box duration in a group of cows and to analyze the effect of milking management practices on milking efficiency.

Key words: quarter milk flowrate, simulation model, milking duration, box time, automatic milking system

\section{INTRODUCTION}

The milking process represents one the most important tasks on a dairy farm. On farms with conventional milking systems, it accounts for roughly a third of farm's total labor demand (Deming et al., 2018). For farms with automatic milking systems (AMS, robots) the large initial capital investment requires that high levels of milking efficiency are achieved to justify the technology used. A key part of the profitability of the system depends on the milk harvested by the robot each day, which in turn depends on the number of cows milked and the number of milkings per cow per day (Castro et al., 2012). Because the box-style AMS can milk one cow at a time, each individual milking is important, and therefore, milking management strategies that can optimize cows milked per day and milk harvested per AMS per day have an effect on system profitability. 
Strategies such as increasing the teatcup removal setting (i.e., testing different milk flowrate switch-points for teatcup removal; Krawczel et al., 2017; Silva Boloña et al., 2019), optimizing teatcup attachment order (Penry et al., 2018), optimizing the milking interval (i.e., the time between 2 successive milkings) of each cow (André et al., 2010), or adjusting the vacuum level and pulsation settings (Reinemann et al., 2001; Upton et al., 2019) can reduce individual milking duration and optimize the capacity of the AMS. Moreover, quarter milking information has become available with the use of AMS which creates the opportunity of exploring milking management practices at the quarter level to improve milking efficiency.

Some of the challenges of empirical hypothesis testing include the lack of repeatability (unless repeating that same experiment), difficulty to control certain parameters (for example milking interval) or the requirement of long periods of observation (Halachmi, 2009). Therefore, sometimes it is preferable to resort to modeling techniques or simulation. Historically, modeling has focused mainly on prediction of daily total milk yield per cow or herd over a lactation cycle (Brody et al., 1924; Wood 1967; Murphy et al., 2014) or per milking session (Gasqui and Trommenschlager, 2017). Wood's model is one of the most widely used models for estimating average daily milk yield in any given day of lactation and follows an incomplete gamma function. Gasqui and Trommenschlager (2017) developed a mechanistic model for estimating milk yield at every milking session in which they considered milk yield per milking as a function of milking interval, proportion of activated alveoli (which is related to stage of lactation), the maximum volumetric capacity of the udder, and milk secretion rate.

Recent research has estimated milk yield at the quarter level and in AMS, taking into account variable milking intervals. Adriaens et al. (2018) used a modification of Wood's model for estimating milk yield at the quarter level and at each milking, considering milking interval, DIM, and quarter position. They found that both DIM and milking interval contributed strongly to quarter milk yield, even more so than quarter position. Jensen et al. (2018) and André et al. (2010) created prediction models for cow milk production in an AMS. They predicted either relative milk yield (i.e., the fraction of daily milk yield that is expected at a time $t$, which is the time after a given milking interval) or milk production rate as a second degree polynomial function.

Fewer studies have modeled or described milking duration. Bickert et al. (1972) and Burks et al. (1998) showed that milking duration is an important component of milking efficiency. Cooper and Parsons (1998) modeled the relationship in AMS between milking duration and milk yield as linear effect. André et al. (2010) reported that the proportion of milking duration that did not depend on milk yield (accumulated intercept) was between 30 and 50\%; however, this included time used for cleaning teats, teat detection, and attachment (André et al., 2010). Most modeling efforts have been aimed at predicting milk production over the course of a lactation or between milking sessions at the udder or quarter level. Models for estimating milking duration, especially at the quarter level are less common. A model that incorporates different variables such as milking interval, quarter variability, stage of lactation, teatcup attachment, and removal settings to estimate quarter, cow, and herd milking durations would provide new knowledge to the existing literature to help evaluate the effect of several milking management practices (e.g., earlier teactup removal or reducing milking interval) on milking efficiency, allowing for an increase in cows milked by the AMS, and hence, higher profitability.

The objectives of this research were (1) to develop a model that can simulate a herd of cows with several milkings and each with their quarter milk flowrates in 1-s intervals, incorporating effects of milking interval, milk production rate, teatcup attachment order, and teatcup removal settings, and use the simulation to predict quarter and udder milking durations and box duration (time that cows spend in the AMS) for a herd milked with quarter milking technology such as that used in AMS; (2) to validate the model by comparing the outcomes of the simulation with empirical data from a commercial AMS dairy farm; and (3) to apply different teatcup removal settings to the simulation to predict its effect on quarter and cow milking duration and box duration in an AMS.

\section{MATERIALS AND METHODS}

This research consisted of 3 steps. The first step was model development, where we created the model structure to perform a simulation. This included fitting functions to parameters from data sets of commercial herds and understanding the mathematical functions that described the different variables of the model. The second step was simulation, in which we used that structure, fitted parameters, and functions mentioned previously to create a herd of cows with an assigned parity, DIM, and milk production rate. For each cow, we simulated several milkings and created instantaneous quarter milk flowrates per milking. With this information, we calculated quarter and cow milking duration and box duration. The third step was application of different milk flowrate switch-points (flowrate at which teatcups are removed) to the milkings of the simulated 
Table 1. Summary statistics of the 2 data sets used for model development

\begin{tabular}{|c|c|c|c|c|}
\hline \multirow[b]{2}{*}{ Variable } & \multicolumn{2}{|c|}{$\begin{array}{l}\text { Data set } 1 \\
(\mathrm{n}=617)\end{array}$} & \multicolumn{2}{|c|}{$\begin{array}{c}\text { Data set } 2 \\
(\mathrm{n}=558,627)\end{array}$} \\
\hline & Mean & $\mathrm{SD}$ & Mean & $\mathrm{SD}$ \\
\hline Quarter yield/milking (kg) & 3.8 & 1.5 & 3.1 & 1.1 \\
\hline Udder yield/milking (kg) & 14.8 & 5.7 & 12.1 & 4.4 \\
\hline Box duration (s) & - & - & 520 & 175 \\
\hline Milking interval (h) & 10.3 & 2.2 & 8.5 & 3.0 \\
\hline Quarter milk production rate $(\mathrm{kg} / \mathrm{h})$ & - & - & 0.4 & 0.2 \\
\hline DIM & - & - & 162 & 111 \\
\hline Lactation & - & - & 2.3 & 1.2 \\
\hline
\end{tabular}

cows to estimate their effect on milking duration and milk yield. In this paper we refer to "the model" (or simulation model) as the structure and functions that allowed us to create the simulation.

\section{Simulation Model Development}

Data Sets. We obtained data of quarter milk flowrates from one AMS (DeLaval International AB) commercial farm located in Northern Germany milking 62 cows. Cows were housed in freestalls and fed a partial mixed ration diet with supplementary feed provided in the robot. This data set contained information from quarter and cow milking duration and milking interval from milkings occurred in the month of November 2019 (data set 1). Milk flowrate $(\mathrm{kg} / \mathrm{min})$ was recorded for each quarter in $2 \mathrm{~s}$ intervals. Data set 1 contained information of more than 3,600 quarter milkings. These milk flowrates were smoothed by calculating the backward 30-s rolling average milk flowrate (the most recent second and the 29 previous ones).

A second data set (data set 2) with over 2,800,000 quarter milkings from a commercial dairy farm operating 32 AMS (DeLaval International AB) located in northeast United States and milking over 1,500 cows from February to December 2015 was also used. Cows were housed in freestalls and fed a partial mixed ration diet with supplementary feed provided in the robot. Data set 2 contained cow and quarter milk yield per milking, cow milking duration and quarter milking duration, milking interval (h), DIM and lactation. Quarter milk production rate (QMPR) was calculated by dividing quarter milk yield by the milking interval for every milking and incorporated into data set 2 .

Data set 1 contained information from highly detailed milk flowrate data on relatively few cows, whereas data set 2 had detailed information on milking duration and milk yield on relatively many cows and with one milking permission (i.e., the time after a milking that cows were allowed to be milked again) for all cows, which had minimal effect on milking interval distribution.
Due to the highly detailed information on data set 1 and to facilitate the fit of the quarter milk flowrate function to the data, a random sample of $20 \%(n=623)$ of the quarter milkings with their flowrate information were selected for model development. For data set 2, due to the size of this data set, a stratified sampling approach was used to extract a random selection of $8 \mathrm{~d}$ of data per month which was used for model development and validation $(\mathrm{n}=642,783$ quarter milkings, $23 \%$ of the full data set). For data set 2, a second random selection of 7 of the $8 \mathrm{~d}$ per month $(\mathrm{n}=558,627,86 \%$ of the subset) were used for model development whereas $1 \mathrm{~d}$ per month $(84,156,14 \%$ of the subset) was used for validation of the simulation. Table 1 shows information and descriptive statistics for the 2 data sets used. These sampling procedures were carried out to facilitate computational processing capacity.

For both data sets, a filtering step was carried out to eliminate observations that appeared corrupted or were outside normal ranges. For data set 1, we removed data of quarter milkings with a milk flowrate of 0 or near 0 throughout the milking. This filtering process removed $1 \%$ of the data in data set 1 , which resulted in 617 quarter milkings being used. For data set 2, data that appeared to be incorrectly recorded or with part of a data sequence missing, resulting in an unusually long or short apparent milking interval, incomplete milking, or milking immediately after an incomplete milking were identified. Milking intervals recorded as shorter than 3 $\mathrm{h}$ and longer than $24 \mathrm{~h}$ were removed. These thresholds were selected because usually AMS have a minimum time before cows are allowed to milk again and because milking intervals $>24 \mathrm{~h}$ are very undesirable and rare. Additionally, if QMPR was lower than $0.05 \mathrm{~kg} / \mathrm{h}$ or greater than $3 \mathrm{~kg} / \mathrm{h}$ they were removed from data set 2 to remove data that was outside the normal ranges. This filtering removed $4 \%$ of the development and validation portion of data set 2 , leaving 617,072 records available.

The variables chosen for inclusion in the simulation model were selected based on significant associations 
with quarter milk yield, milking duration, or box duration reported in the literature. The variables included in the simulation model were QMPR, milking interval, DIM, lactation, teatcup attachment time (AT), teatcup removal settings, preparation time (PT; i.e., time from cow entering the robot to first teatcup attached), and for the $1 \mathrm{~s}$ quarter milk flowrates submodel, peak milk flowrate, rate of increase or decrease of the milk flowrate in a milking, and time at which the flowrate is half its maximum in the increasing or decreasing sections of the milking. The workflow of the model is illustrated in Figure 1 and Figure 2. The outcomes of the simulation were quarter milking duration (QMD) for each quarter, cow milking duration (CMD), and box duration (BD) for each cow in the simulated herd. The simulation was structured as a multilevel simulation and was executed in SAS (SAS 9.4, SAS Institute Inc.). The simulation process (the process of generating a herd of cows and milkings and quarter milk flowrates for each of those milkings) and calculated outcomes are detailed in the following sections.

Herd Characteristics. The first step in the simulation was to create a group of $n$ cows (with 4 quarters each). Each cow was randomly assigned a lactation number and DIM. The distribution functions of DIM and lactation were estimated by fitting several distributions (normal, lognormal, and gamma) to data set 2 using the PROC UNIVARIATE procedure in SAS and selecting the best fitting form of distribution based on the Kolmogorov-Smirnov statistic and by comparing the actual with the estimated quantiles of the distribution. The mean, standard deviation (SD), shape, and scale parameters were obtained from the distribution that fitted the data best. The simulated cows were assigned a DIM and lactation by performing a random sampling procedure from the fitted distributions. This was a static model and therefore only simulated one DIM per cow.

Herd Average Milk Production Rate. We determined the herd's average cow milk production rate (HMPR) as a function of lactation and DIM. The incomplete gamma function described by Wood (1967) was fit to the herd's average daily cow milk production rate for each DIM for 3 lactation groups: first lactation, second lactation, and third or more lactation. The HMPR was averaged for every DIM using the PROC MEANS procedure in SAS 9.4 (SAS Institute Inc.). Wood's curve was then fitted using the PROC NLIN procedure in SAS 9.4 (SAS Institute Inc.) according to the following equation for each lactation group:

$$
H M P R_{\text {ldim }}=\left(a \times D I M^{b} \times e^{(-c \times D I M)}\right)
$$

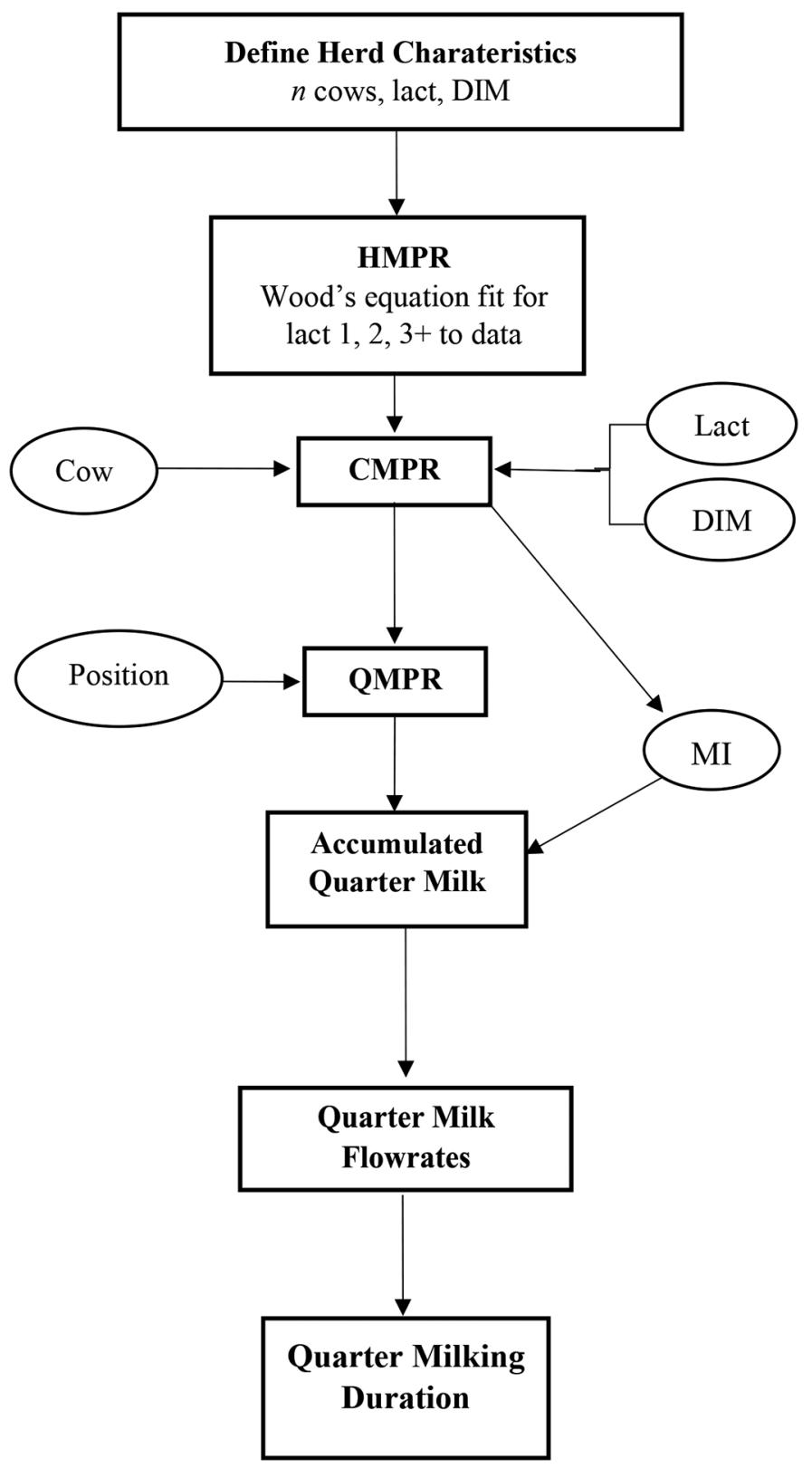

Figure 1. Flow diagram of the simulation process. The first step created a herd of $n$ cows with their corresponding lactation and days in milk. Wood's function was combined with DIM, lactation, and a cow random effect, to calculate CMPR. Each quarter was assigned a fraction of CMPR, depending on position, to obtain QMPR. Several milkings of each cow were simulated by assigning a random milking interval to each cow milking. Milking interval was multiplied by QMPR, to obtain accumulated quarter milk. Using accumulated quarter milk, we constructed the quarter milk flowrates for each cow milking. With the milk flowrates, quarter milking duration was calculated. Lact = parity of the cow; HMPR = herd average milk production rate; CMPR $=$ cow milk production rate; cow $=$ cow random effect; $\mathrm{QMPR}=$ quarter milk production rate; $\mathrm{MI}=$ milking interval; position $=$ front and rear quarters. 


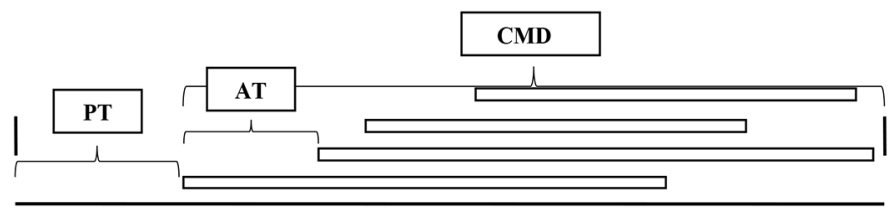

BOX DURATION

Figure 2. Calculation of cow milking duration and box duration. $\mathrm{CMD}=$ cow milking duration; $\mathrm{AT}=$ attachment time, time to attach each teatcup; $\mathrm{PT}=$ preparation time, time from the cow entering the automated milking system to first teatcup attachment. Horizontal bars indicate quarter milking duration. Time units for all variables are seconds.

where $H M P R_{\text {ldim }}$ is the average cow milk production rate $(\mathrm{kg} / \mathrm{h})$ for the $l$ th lactation group in a given DIM; $a$ is HMPR at the start of lactation, estimated by the average of the productions of the fourth, fifth, and sixth postpartum days; $b$ and $c$ are constants associated with prepeak and postpeak slopes of the curve; and DIM= days in milk of the cows.

To simulate a group of cows with a different HMPR, the model would have to be reparametrized by fitting Wood's curve to a new data set with that HMPR. The output of this first segment of the simulation was establishing an estimated herd milk production rate level and simulating a list of cows each with an assigned lactation and DIM. A simulated cow will then use information from DIM, parity and milking interval to have several quarter milkings, each with their own milk flowrates, milking duration and milk production.

Cow Milk Production Rate and Cow Effect. The cow milk production rates for individual cows (CMPR) were created by applying a random cow effect to the HMPR from Equation 1 for their corresponding lactation group and DIM. The following equation represents the calculation of CMPR:

$$
C M P R_{i}=\left[\left(a \times D I M_{i}^{b} \times e^{\left(-c \times D I M_{i}\right)}\right)\right] \times \operatorname{CowEff}_{i},
$$

where $\mathrm{CMPR}_{\mathrm{i}}$ is cow milk production rate $(\mathrm{kg} / \mathrm{h})$ of simulated cow $i$; a, b, and c are constants from Wood's curve from Equation 1, for the corresponding lactation of simulated cow $i, D I M_{i}$ is days in milk assigned to cow $i$; and CowEff $f_{i}$ is randomly sampled cow effect for cow $i$, where CowEff $\sim \mathrm{N}$ (1, 0.07).

The cow random effect on CMPR was obtained by examining the distribution of the residuals from Equation 1. The cow random effect estimate was expressed as the individual cow fraction of the HMPR adjusted for lactation and DIM. The residuals were normally distributed with a mean value of 1 . The CowEff was randomly sampled from these distributions from each lactation group and explained consistent deviations in a cow's milk production rate.

Milking Interval Assignment. To simulate several milkings of each cow, a milking interval was assigned to the simulated milkings of each cow and was based on CMPR. Cows with greater than average CMPR show lower milking intervals, attributed to a higher motivation to visit the AMS. Also, milk extraction is fundamental to milk secretion and higher milking intervals are associated with increased CMPR. The quartiles of CMPR in data set 2 were identified and the probability distribution function of milking interval was estimated separately for each of these CMPR categories, by fitting several distributions (normal, lognormal and gamma) using the PROC UNIVARIATE procedure in SAS and selecting the best fitting form of distribution based on the Kolmogorov-Smirnov statistic and by comparing the actual with the estimated quantiles of the distribution. The mean, SD, shape, and scale parameters were obtained from the distribution that fitted the data best. For the simulation, cows were categorized based on their CMPR as mentioned above, and for each milking a random sampling process from the best fitting distribution of its corresponding category was performed, to assign a milking interval to a cow.

Quarter Milk Production Rate. At this point, we have a simulated list of cows with an assigned DIM, lactation, milking interval, and CMPR. Then, QMPR was calculated for each quarter of the simulated cows. A random draw for the milk fraction contributed by front versus rear quarters was performed, followed by a random draw of the contribution of right versus left quarters (one draw for front and one draw for rear quarters). Data set 2 was used to develop the distributions of these fractions. The fractions were normally distributed and the mean and SD were used for the random draw process. The resulting quarter fractions were multiplied by CMPR to arrive at QMPR for each quarter of the simulated cows.

Accumulated Quarter Milk. The next step in the simulation process was to calculate the accumulated quarter milk (AQM) available in a milking after a given milking interval. This was calculated as function of QMPR and milking intrval. The calculation for AQM was:

$$
A Q M_{i j m}=Q M P R_{i j} \times M I_{i m}
$$

where $A Q M_{i j m}$ is the accumulated quarter milk $(\mathrm{kg})$ expected for the simulated milking $m$ of the quarter $j$ of cow $i ; Q M P R_{i j}$ is the quarter milk production rate of quarter $j$ of cow $i$ as explained in the quarter milk 
production rate subsection; and $M I_{i m}$ is the milking interval (h), for milking $m$ of cow $i$.

Quarter Milk Flowrates. The next step of the simulation was to create instantaneous (1-s intervals) milk flowrates for each quarter milking of the simulated cows. With that information we were able to draw instantaneous milk flowrates for each quarter and milking. The milk flowrates for a milking were modeled as double sigmoid curves using Equation 4. We chose this function because we deemed it a good choice after looking at graphical representation of the flowrates during a milking (a process that increases, levels off at a plateau, and then decreases) and fits the data well empirically. This equation was fitted to the 30-s rolling average quarter milk flowrate for each cow in data set 1 using the PROC NLIN procedure in SAS 9.4 (SAS Institute Inc.):

$$
Q M F_{i j m}=K_{i j m} \times\left(\frac{1}{\frac{1+e^{\left(-R_{i j m} \times\left(t-B_{i j m}\right)\right)}}{\left.1+e^{\left(-R 2_{i j m} \times\left(t-B 2_{i j m}\right)\right.}\right)}}\right),
$$

where $Q M F_{i j m}$ is quarter milk flowrate $(\mathrm{kg} / \mathrm{min})$ for the $m$ th milking of quarter $j$ of cow $i$ in data set $1 ; K_{i j m}$ is the maximum milk flowrate $(\mathrm{kg} / \mathrm{min})$ of the $m$ th milking for quarter $j$ of cow $i$, where $\mathrm{K}_{\mathrm{ijm}}>0 ; R_{i j m}$ is the parameter related to the rate of increase of the milk flowrate $(\mathrm{kg} / \mathrm{min})$ at time $t=B_{i j m}$, of the $m$ th milking of quarter $j$ of cow $i$, where $R_{i j m}>0 ; R 2_{i j m}$ is the parameter related to the rate of decrease of the milk flowrate at time $t=B 2_{i j m}$, of the $m$ th milking for quarter $j$ of cow $i$, where $R 2_{i j m}<0 ; B_{i j m}$ is time of the milking process (s) when the milk flowrate is half its maximum milk flowrate when milk flowrate is increasing for the $m$ th milking for quarter $j$ of cow $i$, where $B_{i j m}>0$; and $B 2_{i j m}$ is time of the milking process (s) when the milk flowrate is half its maximum milk flowrate when milk flowrate is decreasing for the $m$ th milking for quarter $j$ of cow $i$, where $B 2_{i j m}>0$ and $B 2_{i j m}>B_{i j m}$.

Data from actual quarter milk flowrates from data set 1 were fitted to this model and the mean, SD, and probability distributions of each of these parameters $\left(\mathrm{K}_{\mathrm{ijm}}, \mathrm{R}_{\mathrm{ijm},} \mathrm{R} 2_{\mathrm{ijm}}, \mathrm{B}_{\mathrm{ijm}}\right.$, and $\left.\mathrm{B} 2_{\mathrm{ijm}}\right)$ were calculated. Additionally, the correlation coefficients between these fitted parameters were obtained using the PROC CORR statement in SAS.

To create accurate quarter milk flowrates in 1-s intervals for the simulated cows that accounted for the relationship between quarter milk yield and QMD, it was necessary to relate the simulated cows' AQM to the parameters of the milk flowrate profile in a milk- ing. To do this, we explored which of the milk flowrate parameters was most related to milk yield. Graphical representations of each parameter of the flowrates fit to data set 1 in Equation 4 versus quarter milk yield for cows in data set 1 were visually assessed, followed by linear regressions of each parameter on quarter milk yield. The parameter $\mathrm{B} 2$ has the highest $\mathrm{R}^{2}$, therefore the intercept and slope from the linear regression fitted were used in the simulation.

For the simulation of QMF, each quarter of each simulated cow was assigned an initial estimate of the 5 parameters of the double sigmoid curve. The initial estimates for K, R, R2, and B were randomly sampled from distributions identified for each parameter. The estimate for B2 was calculated as a linear function of the calculated AQM for the simulated cow quarter with the fitted intercept and slope mentioned in the previous paragraph. To account for the high correlation between the parameters of the double sigmoid curve, these initial estimates were used to perform a multivariate normal random draw $[N \sim(\alpha, \Sigma)]$ for each quarter of each simulated cow, where the final parameters for creating the quarter milk flowrates were obtained. Due to the lognormal distribution of $\mathrm{K}$ and $\mathrm{B} 2$ they were log-transformed before the multivariate normal random draw and were back transformed afterward.

Once the final parameters of the double sigmoid curve were obtained for each quarter, the simulated milk flowrates were constructed by applying an iteration of Equation 4 in 1-s increments, inputting the calculated parameters for each cow quarter to obtain instantaneous milk flowrates $(\mathrm{kg} / \mathrm{min})$ every second.

Attachment Time and Preparation Time. Probability distribution functions were fitted to data set 2 for AT and PT using the PROC UNIVARIATE procedure in SAS. The best fitting distribution was selected for each of the variables and mean, SD, shape, and scale parameters were obtained similar to what was mentioned in the Herd Characteristics subsection.

Quarter and Cow Milking Duration and Box Duration. The main outcomes of the simulation were QMD, CMD, and BD. Quarter milking duration was calculated for the simulated cows following the creation of the milk flowrates in 1-s intervals for a milking. It corresponded to the total time in s that there was milk flowrate. A minimum milking duration of 1 min was set for each quarter and a milk flowrate switch-point was set at $0.1 \mathrm{~kg} / \mathrm{min}$. Therefore, QMD was the time $t$ where $t>60 \mathrm{~s}$ and quarter milk flowrate $<0.1 \mathrm{~kg} / \mathrm{min}$. Cow milking duration for each milking of the simulated cows was calculated as the duration in s of the sequence between the first quarter with a teatcup attached and the last quarter with a teatcup detached. Teatcup attachment order followed the criteria of most AMS to 
attach the expected rear slowest quarter first, followed by the other rear quarter and then front quarters. The time elapsed between the attachment of one quarter and the next was randomly sampled from the distribution fitted for AT mentioned in the previous subsection. Box duration represented the time in seconds that a cow spends inside the AMS. It was composed of CMD plus PT, which was randomly sampled for each milking of each cow from the distribution fitted for PT mentioned in the previous subsection (see Figure 2).

\section{Simulation Validation}

Validation of this simulation consisted of graphical assessment and goodness of fit statistics for all the equations that were fitted to the data sets (Equations 1 and 4) and to the distributions fitted for milking interval, DIM, lactation, AT, and PT. For the evaluation of the simulation outcomes (QMD, CMD, and $\mathrm{BD}$ ) we compared the simulated data with actual data from the validation portion of data set 2 . We performed the simulation for the same number of quarter milkings from the same number of cows to that of the validation portion of data set 2. Mean absolute percentage error (MAPE) was calculated by calculating the absolute percentage error for each percentile of the actual data and the simulated data and then averaging them. MAPE was calculated as:

$$
\text { MAPE }=\left(\frac{1}{n} \sum \frac{\mid \text { Actual }- \text { Simulated } \mid}{\text { Actual }}\right) \times 100,
$$

where $M A P E$ is mean absolute percentage error; $n=$ the number of percentiles, $n=100$; Actual is actual data in the validation portion of data set 2; and Simulated is simulated data.

A MAPE of $<20 \%$ was considered a good fit for the model based on results reported by Adriaens et al. (2018). Additionally, probability plots were constructed to compare the estimated outcome variables to the observed variables. A comparison of the distributions of the main variables between the actual and simulated data was calculated using the Kolmogorov-Smirnov statistic. The simulated 1-s interval quarter milk flowrates were also graphically compared with the fitted quarter milk flowrates in data set 1 to assess that the simulated flowrates follow a similar pattern and repeatability to those of the actual cows.

\section{Simulation Application}

We assessed the applicability of our simulation by replicating the Silva Boloña et al. (2019) and Silva Boloña et al. (2020) trials that evaluated the effect of teatcup removal settings on QMD, CMD, and BD. A set of quarter level absolute milk flowrate-based settings consisted of removing teatcups at $0.2 \mathrm{~kg} / \mathrm{min}$ (MFR0.2), $0.4 \mathrm{~kg} / \mathrm{min}$ (MFR0.4), and $0.6 \mathrm{~kg} / \mathrm{min}$ (MFR0.6). A set of quarter level percentage-based settings consisted of removing the teatcups at $20 \%$ of the quarter's $30-\mathrm{s}$ rolling average milk flowrate (MFR20), 30\% of the quarter's 30-s rolling average milk flowrate (MFR30), and at $50 \%$ of the quarter's 30 -s rolling average milk flowrate (MFR50). A mixed model was used to assess the effect of treatment on QMD, CMD, BD, strip milk, and milk yield. The mixed model accounted for the fixed effects of treatment, DIM, lactation, milking interval, and the random effect of cow.

\section{RESULTS}

\section{Model Development}

Table 1 shows descriptive statistics for the 2 data sets used for the development of this simulation model. The portion of data set 2 used for model development consisted of 558,627 quarter milkings, which represented 143,364 cow milkings from 1,513 cows. The fit of Wood's curve in Equation 1 for lactations 1, 2, and $3+$ is shown in Figure 3. The MAPE of Wood's model was $4.1,3.3$, and $4.2 \%$ for lactations 1,2 , and $3+$ respectively, showing that the curve was a good fit for HMPR (Figure 4). The parameters obtained by fitting Equation 1 to the average daily HMPR are shown in Table A1 of the appendix. The distributions fitted for milking interval (per CMPR category), DIM, lactation, $\mathrm{AT}$, and $\mathrm{PT}$, and the parameters of these distribution functions are presented in Table A2 in the appendix. Random cow effect was normally distributed with a mean of $1 \mathrm{~kg} / \mathrm{h}$ and an SD of $0.07 \mathrm{~kg} / \mathrm{h}$, which represented $\pm 5 \%$ of the average cow milk production rate. The fraction of CMPR that was contributed by rear quarters was normally distributed with a mean of 0.55 and SD of 0.09; consequently, the fraction of CMPR contributed by front quarters was normally distributed with a mean of 0.45 and SD 0.09. Within each quarter position (left and right rear or front quarters), quarter contribution was normally distributed with a mean 0.5 and SD 0.08 .

The average quarter flowrate for cows in data set 1 was $1.0 \mathrm{~kg} / \mathrm{min}$ (SD $0.3 \mathrm{~kg} / \mathrm{min}$ ). Overall, the double sigmoid curve fitted the quarter milk flowrates in data set 1 with a mean squared error of less than $0.005 \mathrm{~kg} /$ min (0.003 for front and 0.008 for rear quarters). The fitted parameters of the quarter milk flowrates are shown in Table A3 of the appendix. There was great variability in the parameters between quarter, cows and 
Quarter milking duration (min) from the simulation;

Quarter milking duration from the Silva Boloña et al. (2020) study;

$\mathbf{\Delta}$ Quarter strip milk (kg) from the simulation;

$\square$ Quarter strip milk (kg) from the Silva Boloña et al. (2020) study.

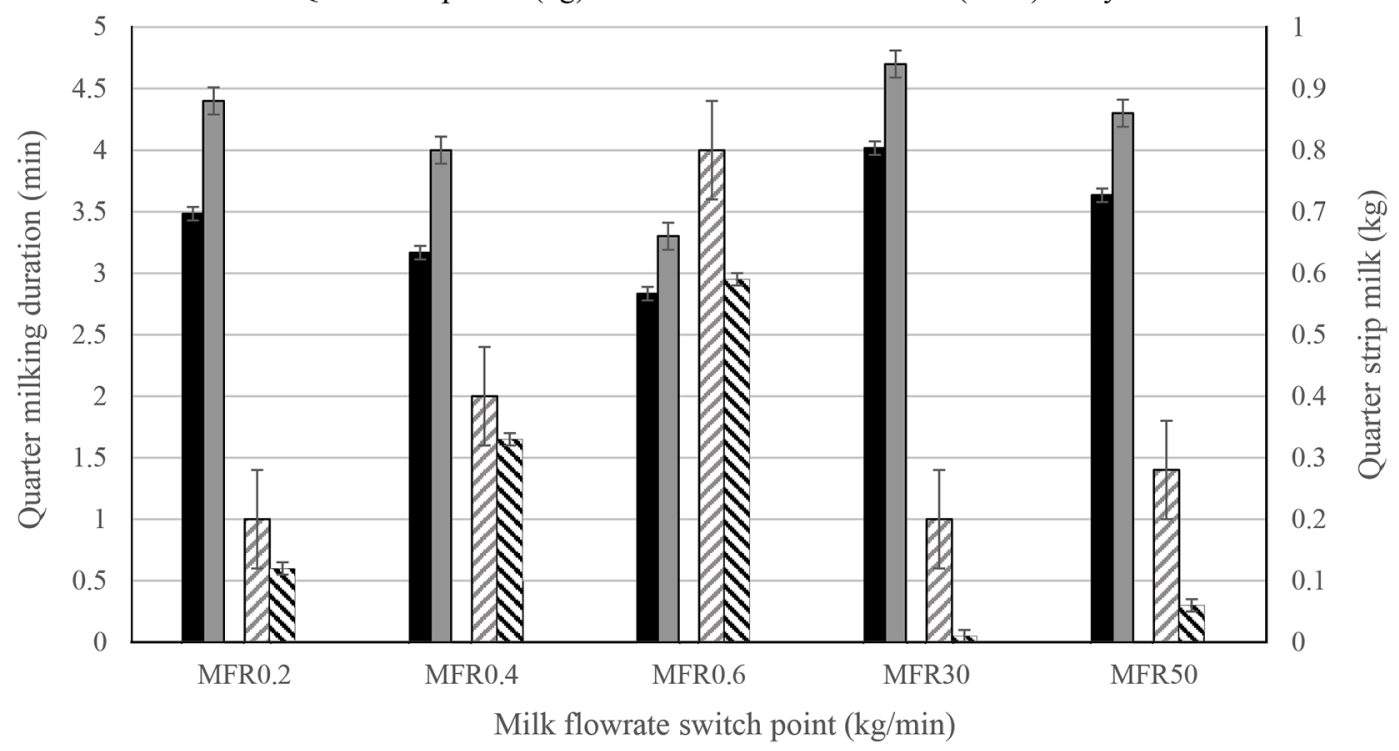

Figure 3. Effect of quarter teatcup removal settings on quarter milking duration and strip milk across both simulated data and previously collected data for quarter milking duration ( $\min$ ) from the simulation, quarter milking duration from the Silva Boloña et al. (2020) study, quarter strip milk $(\mathrm{kg})$ from the simulation, and quarter strip milk $(\mathrm{kg})$ from the Silva Boloña et al. (2020) study. MFR0.2 = teatcup removal at $0.2 \mathrm{~kg} / \mathrm{min}$; MFR0.4 = teatcup removal at $0.4 \mathrm{~kg} / \mathrm{min}$; MFR0.6 = teatcup removal at $0.6 \mathrm{~kg} / \mathrm{min}$; MFR30 = teatcup removal at $30 \%$ of the average flow rate; MFR50 = teatcup removal at $50 \%$ of the average flow rate. Values represented by the bars correspond to the LSM estimates and the error bars to the SEM.

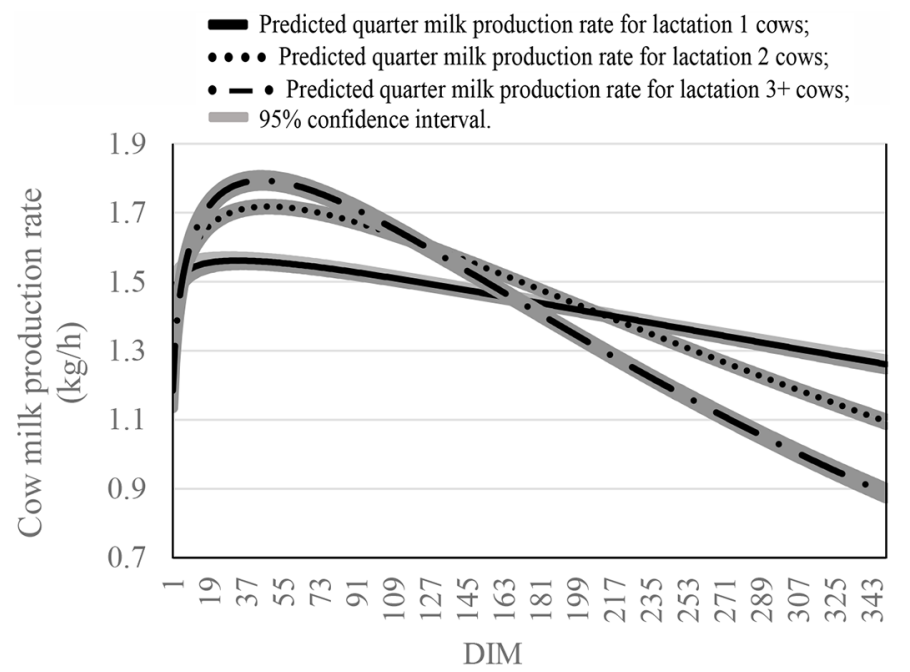

Figure 4. Fitted herd's average cow milk production rate using Wood's equation for lactations 1,2 , and $3+$. Predicted quarter milk production rate for lactation 1 cows (solid line); predicted quarter milk production rate for lactation 2 cows (dotted and dashed line); predicted quarter milk production rate for lactation $3+$ cows (dotted line); and $95 \%$ CI (thicker gray line for each lactation). milkings. For example, $\mathrm{K}$ (maximum milk flowrate) ranged from $0.3 \mathrm{~kg} / \mathrm{min}$ to $4.3 \mathrm{~kg} / \mathrm{min}$. Figure A1 in the appendix shows the fit of the double sigmoid curve to quarter milk flowrate in a sample cow from data set 1. R-squared for the linear regressions of the double sigmoid curve parameters on quarter milk yield from data set 1 were $0.6,0.001,0.001,0.01$ and 0.05 for $\mathrm{B} 2, \mathrm{~B}, \mathrm{R}$, $\mathrm{R} 2$ and $\mathrm{K}$ respectively, indicating that the parameter of the milk flowrates that was more related to milk yield was B2 (time of the milking process when the milk flowrate is half its maximum milk flowrate, when milk flowrate is descending).

\section{Simulation Validation}

The validation portion of data set 2 had 84,156 quarter milkings which corresponded to 21,617 cow milkings from 1,506 cows. Average CMPR for the simulated cows was $1.5 \mathrm{~kg} / \mathrm{h}$. The MAPE of the simulated versus the actual data for milking interval was $2.7 \%$. Figure A2 in the appendix shows a graphical comparison of the distributions of milking interval and quarter milk yield for the actual and the simulated data. The simulation was able to replicate the distribution of QMD for the actual data with a MAPE of $7.5 \%$. The CMD had a MAPE of 
Table 2. Milking performance variables from the simulated and actual data ( $\mathrm{n}=84,156$ quarter milkings)

\begin{tabular}{lccccc}
\hline & \multicolumn{2}{c}{ Simulation } & & \multicolumn{2}{c}{ Actual } \\
\cline { 2 - 3 } \cline { 5 - 6 } Variable & Mean & SD & & Mean & SD \\
\hline Quarter milking duration (s) & 212 & 96 & & 199 & 88 \\
Quarter milk yield (kg) & 3.3 & 1.8 & & 3.1 & 1.3 \\
Cow milking duration (s) & 415 & 95 & & 410 & 121 \\
Box duration (s) & 510 & 97 & & 509 & 120 \\
\hline
\end{tabular}

$8.8 \%$ when comparing the simulated versus the actual percentiles, whereas simulated BD had a MAPE of $12 \%$ compared with the actual data. Figure A3 in the appendix shows the probability plots for the simulated versus the actual percentiles for QMD, CMD and BD. Table 2 shows descriptive statistics for QMD, CMD, $\mathrm{BD}$ and quarter milk yield of the simulation and actual data. Empirical distribution functions for QMD, CMD and $\mathrm{BD}$ were compared for these 3 outcome variables and the Kolmogorov-Smirnov statistic had a P-value $>0.2$ showing that the actual and simulated values followed similar distributions. Figure A4 in the appendix shows an example of the simulated $1 \mathrm{~s}$ interval quarter milk flowrates for 2 randomly chosen cows of the simulated herd.

\section{Simulation Application}

Figure 3 shows the least squares means estimates and standard errors for quarter strip milk and milking duration for the teatcup removal settings application experiment. Additionally, Figure 3 includes the results from Silva Boloña et al. (2020) to illustrate the results of the application of the simulation. Figure 5 shows the effect of the teatcup removal setting on cow milk yield, strip milk and milking duration for the application of this simulation. We found statistical difference between all the treatments on $\mathrm{QMD}, \mathrm{CMD}, \mathrm{BD}$, quarter milk yield and quarter strip milk. The MFR30 treatment had 4\% shorter CMD than MFR20. Silva Boloña et al. (2019) reported a $3 \%$ difference for those treatments. We found a $3 \%$ difference in BD between the MFR20 and MFR30 treatments (equal to that of Silva Boloña et al., 2019). The MFR50 treatment had a $6 \%$ and $10 \%$ lower CMD compared with the MFR20 and MFR30 treatments respectively, which does not agree to that reported in the Silva Boloña et al. (2019) trial. For QMD we found a $9 \%$ difference between using a $0.4 \mathrm{~kg} / \mathrm{min}$ switch-point compared with $0.2 \mathrm{~kg} / \mathrm{min}$ (equal to Silva Boloña et al., 2020). Quarter strip milk which was 0.2 $\mathrm{kg}(6 \%$ of total QMY) in our simulation compared with $0.2 \mathrm{~kg}(7.3 \%$ of total quarter milk yield) found in the previously mentioned trial. There were no differences in cow milk yield per milking between the MFR20 and
MFR30 treatments similar to that reported by Silva Boloña et al. (2019). For the absolute milk flowrate swtich-points, all treatments were different in cow milk yield per milking (Figure 4).

\section{DISCUSSION}

We developed, validated and applied a simulation model based on creating quarter milk flowrates for an entire milking to estimate quarter and CMD and BD. Creating a simulation model provides comparative advantages to performing experiments such as repeatability of the results, the possibility of conducting a simulation of large number of cows and milkings and the possibility to control for parameters that might be difficult to control in experimental settings (Halachmi, 2009).

To our knowledge there are no other models that simulate milking duration at the quarter and cow level in the literature. André et al. (2010) optimized AMS capacity and incorporated a model to predict CMD that included milk yield as an independent variable, however milking duration in that study also included PT. Adriaens et al. (2018) created a model to estimate short-term quarter milk yield in an AMS which included the milking interval variable. Jensen et al. (2018) developed a dynamic model for estimating cow milk yield in AMS. Our model is unique in that we chose to predict milking duration as the main outcome because it is directly related to milking efficiency in AMS. By allowing more cows to be milked or more milkings per cow, milk harvested by the robot in a year and the profitability of the system increases (Castro et al., 2012). Reinemann et al. (2019) showed that milk harvested per unit of BD and the total time the box is occupied contributed to $99 \%$ of the variation in milk/box per day, showing the relationship between $\mathrm{BD}, \mathrm{CMD}$ and milking efficiency. Our model did not include postmilking teat disinfection as part of BD because this time was very short ( 7 to 8 s) and varied very little, therefore to create a simpler model we decided to exclude this time.

Other studies have described the effect of milking interval on accumulated milk as a second-degree polynomial function. However, André et al. (2010) 
mentioned that the great variability in milk yield per milking found between cows was more related to the initial milk secretion rate than the quadratic effect. We decided to describe it as a linear function because when exploring the test data set, the linear function was a better fit and because the negative effect on milk yield for the simulated milking intervals would be very small and therefore chose a simpler linear function.

The creation of the quarter milk flowrates in $1 \mathrm{~s}$ intervals for a milking and their use to estimate QMD was also a novel approach in this model. This allows for the modification of teatcup removal settings to estimate their impact on quarter and CMD as well as BD. It also provided understanding of the relationship between quarter milk yield and milking duration by highlighting the relationship between quarter milk yield and the parameter B2 (time at which flowrate is half its maximum when milk flowrate is descending). This is supported by the study of Weiss et al. (2004) who reported a positive correlation of increased milk yield and increased milking duration. Weiss et al. (2004) also showed a negative correlation between decreased milking duration with increased peak flowrate and our study showed a negative correlation between the $\mathrm{K}$ and $\mathrm{B} 2$ parameters in the milk flowrate (data not shown). Relating B2 to quarter milk yield and performing a multivariate draw allowed us to estimate the milk flowrates based on different quarter milk yield levels, therefore we expect these flowrates could be estimated for other herds without losing accuracy in predicting QMD, however this needs to be tested. Our data sets did not have sufficient information to relate all the milk flowrate parameters to other cow related variables which is why our approach was oriented at estimating milk flowrates for the herd rather than to predict a specific instantaneous milk flowrate for each cow. Generating quarter milk flowrates for the entire milking in the simulation required an iterative process that calculated milk flowrates for every second of the milking of each quarter. This resulted in more than 30 million data lines in the simulation which presented a computational challenge and explains our modeling approach of sampling a subset of days from the actual data. We believe the random sample selected is representative of the herd for the entire year and therefore it was an adequate approach to deal with this problem.

Cow milking duration (min); $\square$ Box duration (min); $\mathbf{\$}$ Cow strip milk (kg); $\square$ Cow milk yield (kg)

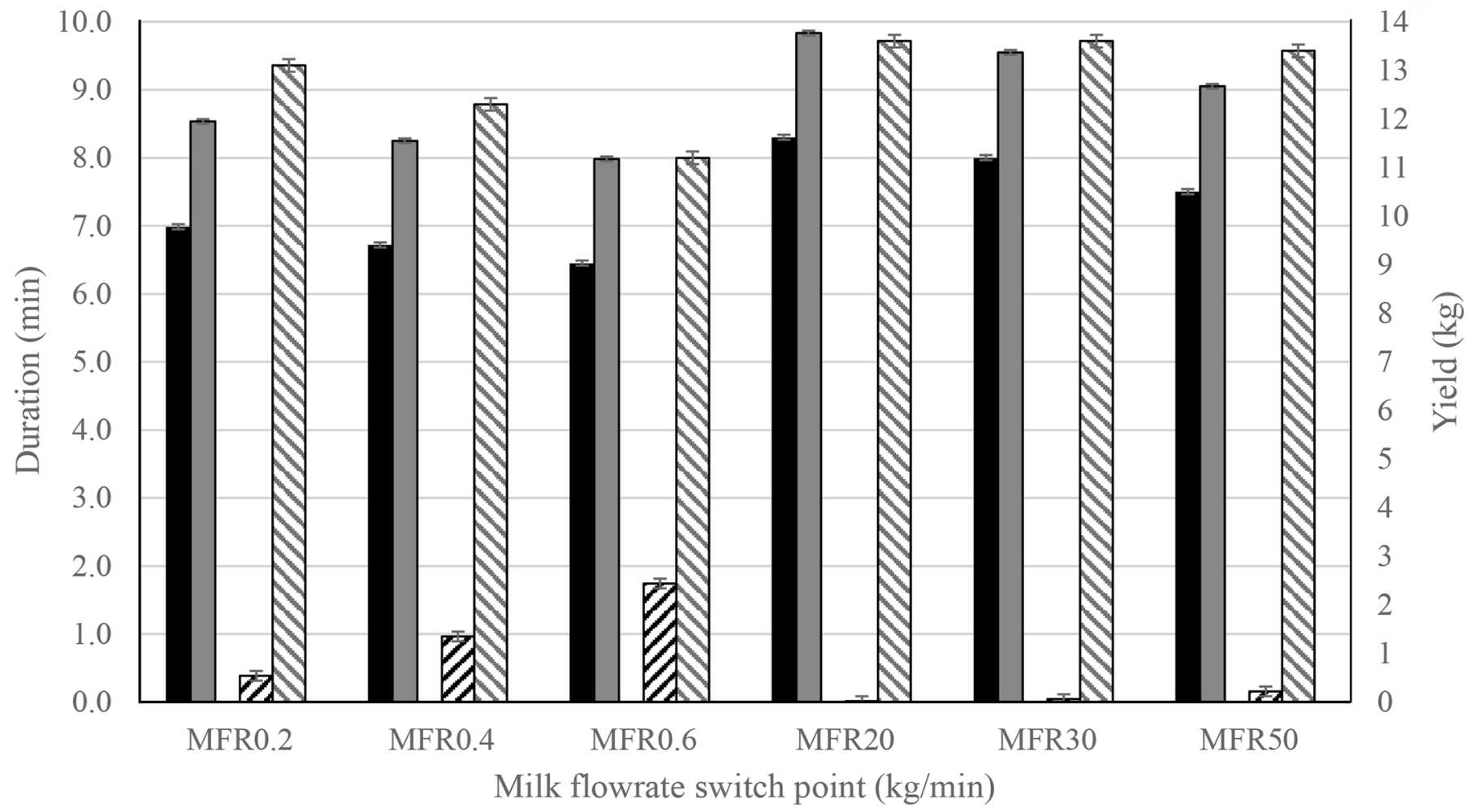

Figure 5. Effect of quarter teatcup removal settings on cow milking duration $(\mathrm{min})$, cow milk yield ( $\mathrm{kg}$ ), cow strip yield (kg), and box duration (min). MFR0.2 = teatcup removal at $0.2 \mathrm{~kg} / \mathrm{min}$; MFR $0.4=$ teatcup removal at $0.4 \mathrm{~kg} / \mathrm{min}$; MFR0.6 = teatcup removal at $0.6 \mathrm{~kg} /$ min; MFR20 = teatcup removal at 20\% of the average flow rate; MFR30 = teatcup removal at $30 \%$ of the average flow rate; MFR50 = teatcup removal at $50 \%$ of the average flow rate. Values represented by the bars correspond to the LSM estimates and the error bars to the SEM. 
This simulation predicted and we compared the responses at the herd level rather than at the individual cow level, hence the approach taken for development and validation. We followed the validation criteria mentioned by Adriaens et al. (2018) that considered a MAPE of between $8 \%$ and $20 \%$ a sufficiently good fit for their model of quarter milk yield, given that measurement uncertainty of the sensors, environmental conditions, concentrate supplementation or disease add variability to the data. The fits achieved for Equations 1 and 4 were considered good, with low MAPE and mean squared error, respectively. Adriaens et al. (2018) found a MAPE of $17.8 \%$ by fitting Wood's function to quarter milk yield over time, which is higher than our results. The fit in our study was performed on the daily average cow milk production rate for the herd, which is a simplified approach compared with Adriaens et al. (2018) and explains this low MAPE. Validation of $\mathrm{QMD}, \mathrm{CMD}$, and $\mathrm{BD}$ showed that the simulation was good at capturing the distribution of these variables and achieving low MAPE between the simulated and actual data, with the largest errors occurring at the extremes of the distributions.

Application of a milk flowrate switch-point to the simulated milkings showed similar results to other trials in the literature for CMD and BD (Silva Boloña et al., 2019). The shorter CMD in the MFR50 was different to that reported in the Silva Boloña et al. (2019) trial, but their teatcup removal setting had a limit that prevented teatcup removal if the milk flowrate was above $0.5 \mathrm{~kg} / \mathrm{min}$, which was not included in this simulation. Our results are also comparable to those of Krawczel et al. (2017) that found a $4 \%$ difference between a switch-point of $0.3 \mathrm{~kg} / \mathrm{min}$ and $0.48 \mathrm{~kg} / \mathrm{min}$ (roughly a $0.2 \mathrm{~kg} / \mathrm{min}$ difference). The simulation found a $4 \%$ reduction in milking duration by using switch-point of $0.4 \mathrm{~kg} / \mathrm{min}$ compared with $0.2 \mathrm{~kg} / \mathrm{min}$ (the same 0.2 $\mathrm{kg} / \mathrm{min}$ difference). Our results also compare well with those of the Silva Boloña et al. (2020) trial for QMD and quarter strip milk showing the usefulness of the simulation to show the effect of this practice in milking duration. The magnitude of the effects was different between our simulation and that of Silva Boloña et al. (2020) because of the different experimental conditions but the percentage variation between the different switch-points was similar. The simulation did not agree with the Silva Boloña et al. (2019) study because we found a $0.2 \mathrm{~kg}$ lower cow milk yield per milking for the MFR50 treatment compared with MFR30. For the absolute milk flowrate switch-points, all treatments were different which is different to what was reported by Krawczel et al. (2017) when applying the switch-point at the quarter level. The difference is that this is a static simulation and there is no accounting for how the quarters adapt in time after an increase in the milk flowrate switch-point. The literature does not provide information on this subject and therefore, we need to collect empirical data to be able to refine the model and accommodate this effect.

This simulation model provides the structure to create a herd with a defined set of characteristics. We expect that this simulation would be accurate in herds similar to the reference herd. Generalizability of the model to other type of herds (e.g., lower milk production rate, seasonal calving pattern or pasture-based AMS) will require reparameterization of some variables, such as Wood's fit to lactation curves and the distribution of lactation, DIM, and milking interval. The structure of the model would remain the same, which was the reason for our modeling approach. Another possibility to adapt the model to other milk yield levels would be to obtain the parameter of Wood's curve as a function of the production level of the herd, but this requires further validation. The scope of this model is to explore how different milking management scenarios such as modifying the milking interval for a subgroup of cows (e.g., cows in early lactation), modifying teatcup removal settings, testing attachment strategies, and cow grouping strategies affect quarter and CMD, BD, and eventually, time spent milking by the robot. An important future inclusion in the model will be to predict the effect of several milking permissions on milking interval. In this simulation, milking permission was equal for all cows. Exploration of empirical data that shows how the milking permission affects milking interval will be relevant for further model development.

\section{CONCLUSIONS}

We developed, validated, and applied a simulation model using quarter milk flowrates to estimate QMD, $\mathrm{CMD}$, and BD. Simulation of quarter milk flowrates is a novel contribution to knowledge, and the model showed that this approach was accurate for simulating QMD. Mean absolute percent error was 7.5, 8, and $12 \%$ for simulated $\mathrm{QMD}, \mathrm{CMD}$, and $\mathrm{BD}$, respectively, compared with actual data. Model application showed that QMD could be reduced by $19 \%$ when increasing the flowrate for teatcup removal from 0.2 to $0.6 \mathrm{~kg} / \mathrm{min}$. By using a teatcup removal setting of $20 \%$ of the quarter's rolling average milk flowrate, QMD was $4 \%$ longer than by using $30 \%$ of the rolling average flowrate.

\section{ACKNOWLEDGMENTS}

The authors acknowledge the financial support of the Teagasc (Teagasc Moorepark, Cork, Ireland) and the University of Wisconsin-Madison (Madison, WI). 
We acknowledge the collaboration of DeLaval (Tumba, Sweden) for the facilitation of the datasets used for model development. The authors have not stated any conflicts of interest.

\section{REFERENCES}

Adriaens, I., T. Huybrechts, B. Aernouts, K. Geerinckx, S. Piepers, B. De Ketelaere, and W. Saeys. 2018. Method for short-term prediction of milk yield at the quarter level to improve udder health monitoring. J. Dairy Sci. 101:10327-10336. https://doi.org/10 $.3168 /$ jds.2018-14696.

André, G., P. B. M. Berentsen, B. Engel, C. J. A. M. de Koning, and A. G J. M. Oude Lansink. 2010. Increasing the revenues from automatic milking by using individual variation in milking characteristics. J. Dairy Sci. 93:942-953. https://doi.org/10.3168/jds .2009-2373.

Bickert, W. G., J. B. Gerrish, and D. V. Armstrong. 1972. Semiautomatic milking in a polygon parlor: A simulation. Trans. ASAE 15:355-0357. https://doi.org/10.13031/2013.37906.

Brody, S., C. W. Turner, and A. C. Ragsdale. 1924. The relation between the initial rise and the subsequent decline of milk secretion following parturition. J. Gen. Physiol. 6:541-545. https://doi.org/ 10.1085/jgp.6.5.541.

Burks, T. F., L. W. Turner, R. S. Gates, T. C. Bridges, and W. L. Crist. 1998. A stochastic simulation model for predicting cow throughputs in dairy parlors. Trans. ASAE 41:1789-1797. https:/ /doi.org/10.13031/2013.17333.

Castro, A., J. M. Pereira, C. Amiama, and J. Bueno. 2012. Estimating efficiency in automatic milking systems. J. Dairy Sci. 95:929-936. https://doi.org/10.3168/jds.2010-3912.

Cooper, K., and D. J. Parsons. 1998. A simulation model of an automatic milking system applying different management strategies. J. Agric. Eng. Res. 69:25-33. https://doi.org/10.1006/jaer.1997 .0219 .

Deming, J., D. Gleeson, T. O'Dwyer, J. Kinsella, and B. O'Brien. 2018. Measuring labor input on pasture-based dairy farms using a smartphone. J. Dairy Sci. 101:9527-9543. https://doi.org/10 $.3168 /$ jds.2017-14288.

Gasqui, P., and J. M. Trommenschlager. 2017. A new standard model for milk yield in dairy cows based on udder physiology at the milking-session level. Sci. Rep. 7:8897. https://doi.org/10.1038/ s41598-017-09322-x.

Halachmi, I. 2009. Simulating the hierarchical order and cow queue length in an automatic milking system. Biosyst. Eng. 102:453-460. https://doi.org/10.1016/j.biosystemseng.2009.01.010.

Jensen, D. B., M. van der Voort, and H. Hogeveen. 2018. Dynamic forecasting of individual cow milk yield in automatic milking systems. J. Dairy Sci. 101:10428-10439. https://doi.org/10.3168/jds .2017-14134.
Krawczel, P., S. Ferneborg, L. Wiking, T. K. Dalsgaard, S. Gregersen, R. Black, T. Larsen, S. Agenäs, K. Svennersten-Sjaunja, and E. Ternman. 2017. Milking time and risk of over-milking can be decreased with early teat cup removal based on udder quarter milk flow without loss in milk yield. J. Dairy Sci. 100:6640-6647. https: //doi.org/10.3168/jds.2016-12312.

Murphy, M. D., M. J. O’Mahony, L. Shalloo, P. French, and J. Upton. 2014. Comparison of modelling techniques for milk-production forecasting. J. Dairy Sci. 97:3352-3363. https://doi.org/10.3168/ jds.2013-7451.

Penry, J. F., P. M. Crump, L. L. Hernandez, and D. J. Reinemann. 2018. Association of quarter milking measurements and cow-level factors in an automatic milking system. J. Dairy Sci. 101:75517562. https://doi.org/10.3168/jds.2017-14153.

Reinemann, D. J., M. A. Davis, D. Costa, and A. C. Rodriguez. 2001. Effects of milking vacuum on milking performance and teat condition. Pages 13-15 in Proc. of the AABP-NMC Symposium, International Symposium on Mastitis and Milk Quality, Vancouver, BC, Canada.

Reinemann, D. J., M. Zucali, V. Inzaghi, P. D. Thompson, J. F. Penry, P. Silva Boloña, and J. Upton. 2019. Prospects for Precision Milking Management in Automatic Milking Systems. European conference on precision livestock farming 2019, Cork, Ireland. Teagasc.

Silva Boloña, P., D. J. Reinemann, and J. Upton. 2019. Effect of teatcup removal settings on milking efficiency and milk quality in a pasture-based automatic milking system. J. Dairy Sci. 102:84238430. https://doi.org/10.3168/jds.2018-15839.

Silva Boloña, P., J. Upton, and D. J. Reinemann. 2020. Effect of simulated quarter and udder teatcup removal settings on strip milk and milking duration in dairy cows. J. Dairy Sci. 103:4446-4454. https: //doi.org/10.3168/jds.2019-17266.

Upton, J., P. S. Bolona, and D. J. Reinemann. 2019. Effects of changing teatcup removal and vacuum settings on milking efficiency of an automatic milking system. J. Dairy Sci. 102:10500-10505. https://doi.org/10.3168/jds.2018-16035.

Weiss, D., M. Weinfurtner, and R. M. Bruckmaier. 2004. Teat anatomy and its relationship with quarter and udder milk flow characteristics in dairy cows. J. Dairy Sci. 87:3280-3289. https://doi.org/ 10.3168/jds.S0022-0302(04)73464-5.

Wood, P. 1967. Algebraic model of the lactation curve in cattle. Nature 216:164-165. https://doi.org/10.1038/216164a0.

\section{ORCIDS}

P. Silva Boloña ๑ https://orcid.org/0000-0002-5866-6943

J. Upton (ㄴ) https://orcid.org/0000-0002-6142-8372

V. Cabrera @ https://orcid.org/0000-0003-1739-7457

T. Erker @ https://orcid.org/0000-0003-2579-2254

D. J. Reinemann ( https://orcid.org/0000-0002-1319-0718 


\section{APPENDIX}
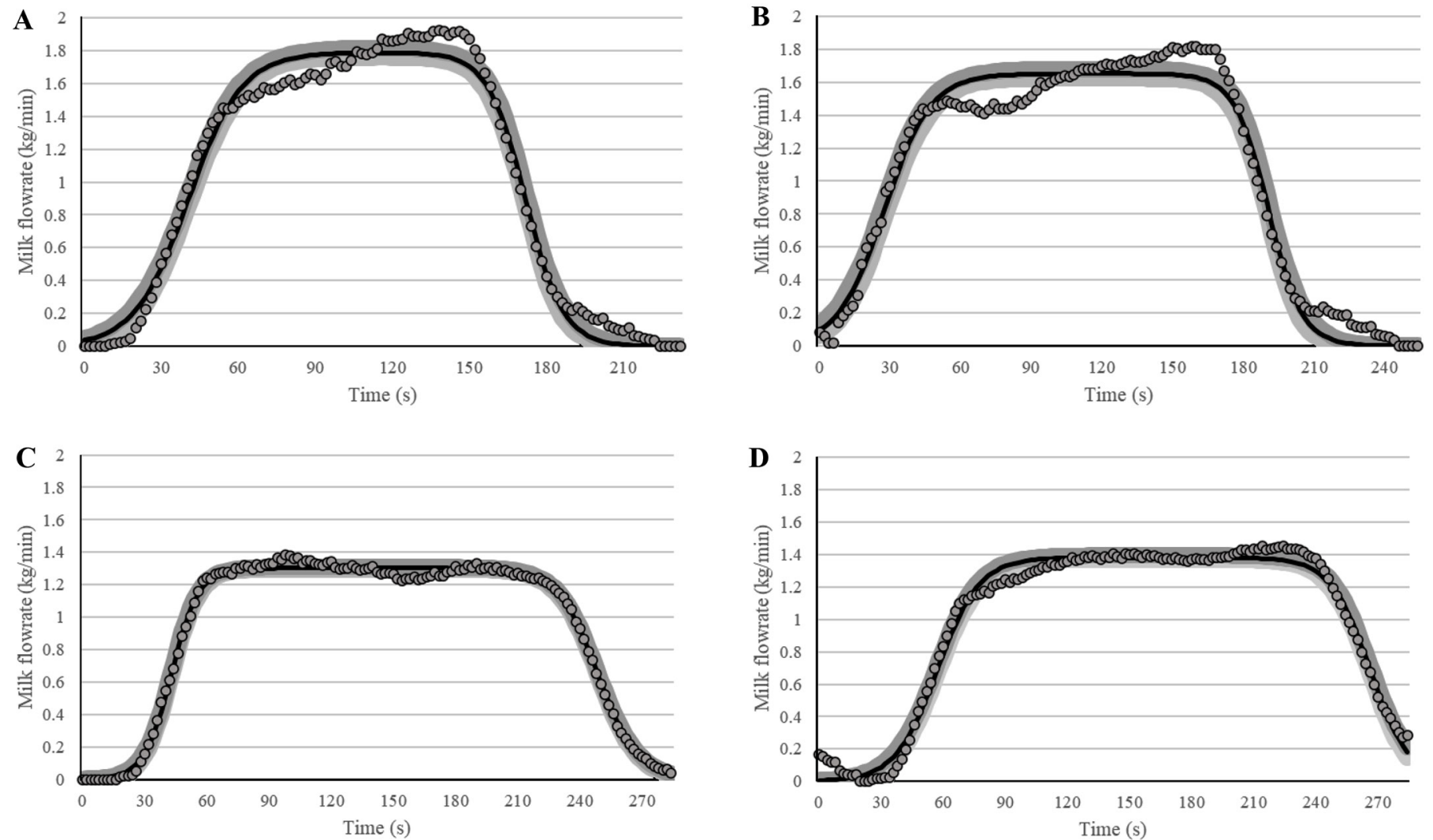

Figure A1. Fitted versus observed graph of the quarter milk flowrates (Equation 1) for a sample milking of a cow in data set 1. For (A) fitted front quarters, mean square error $=0.001 \mathrm{~kg} / \mathrm{min}$; for $(B)$ observed front quarters, $0.001 \mathrm{~kg} /$ min. For $(\mathrm{C})$ fitted rear quarters, mean square error $=0.0008 \mathrm{~kg} / \mathrm{min}$; for $(\mathrm{D})$ observed rear quarters, $0.003 \mathrm{~kg} / \mathrm{min}$. Solid black line $=$ predicted milk flowrate; circles $=$ observed milk flowrate; thick gray line $=95 \%$ CI. 

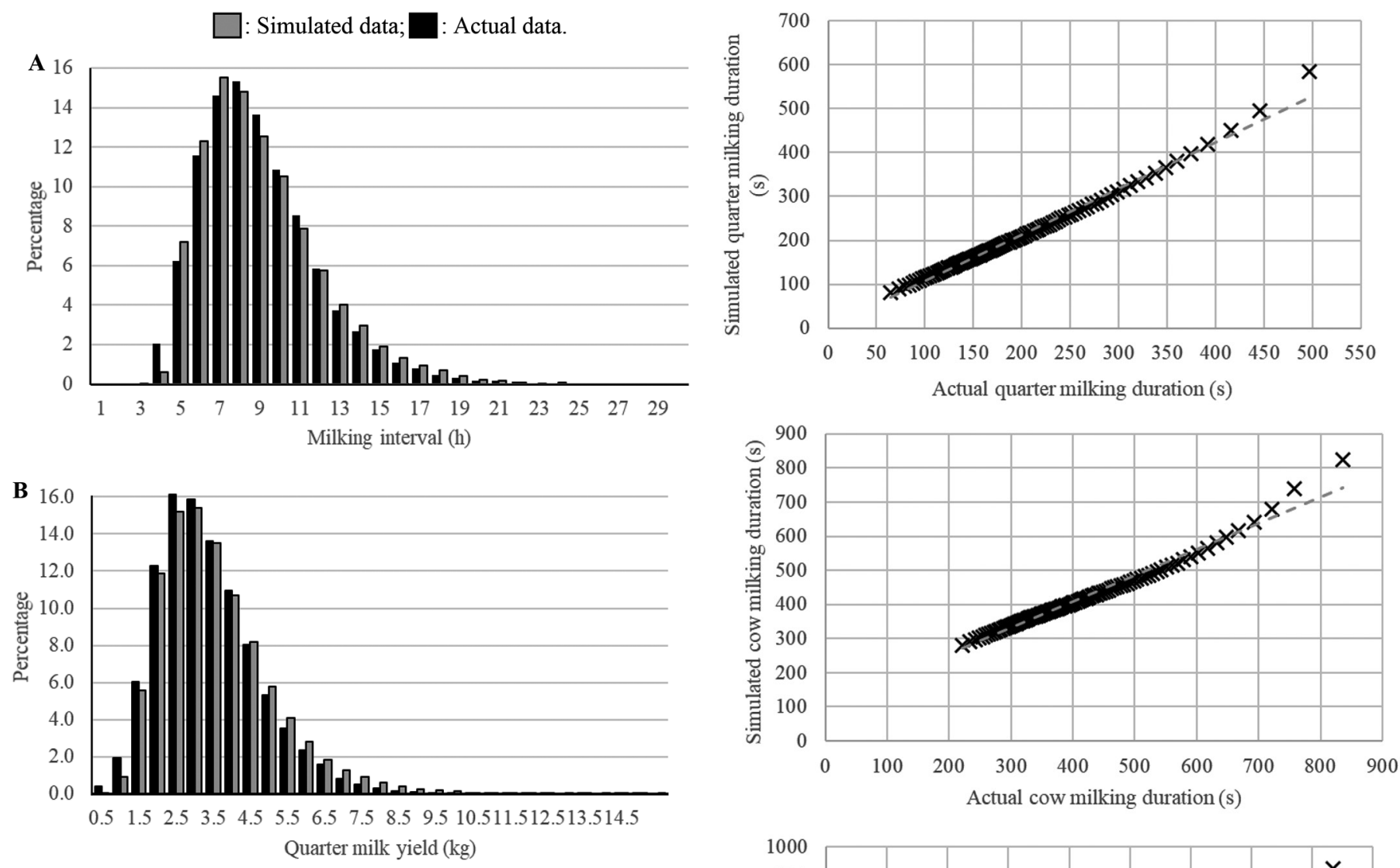

Figure A2. Histogram of the actual and simulated milking interval and quarter yield.

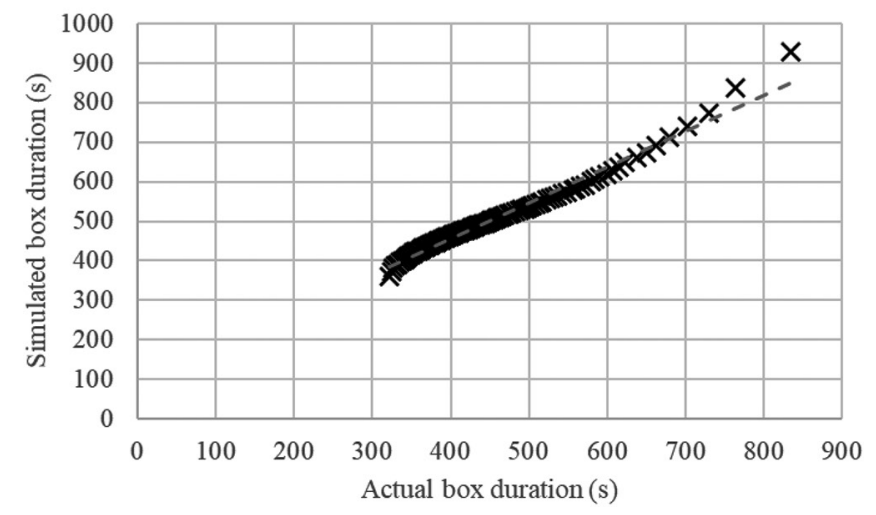

Figure A3. Probability plot of simulated (dashed) versus actual quarter milking duration (x), cow milking duration and box duration for cows in the validation data set. 

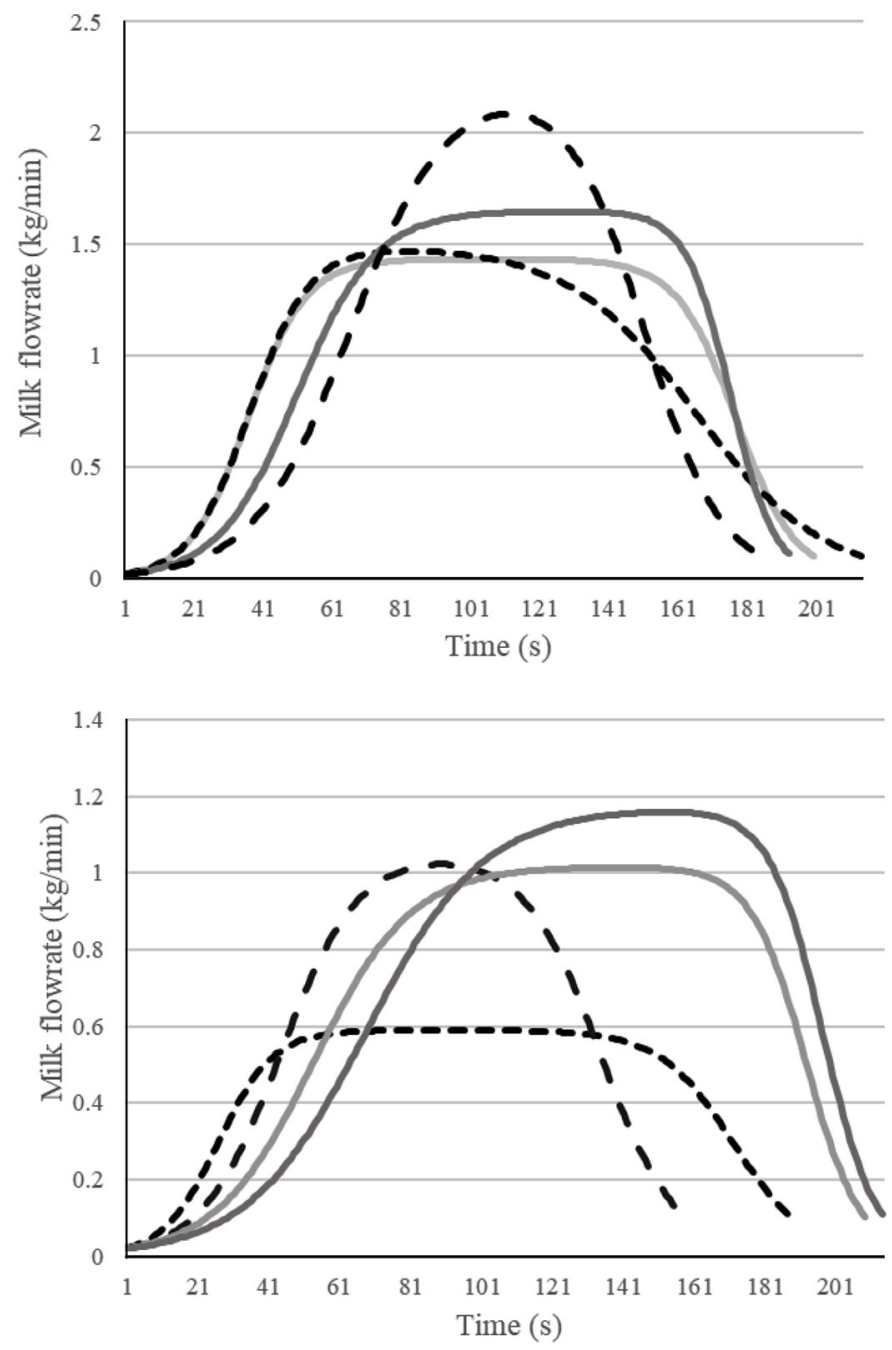

Figure A4. Simulated quarter milk flowrates; each line represents one quarter flowrate of a simulated cow.
Table A1. Fitted parameters of Wood's curve for the 3 lactation categories $^{1}$

\begin{tabular}{lccc}
\hline Parameter & $\mathrm{A}$ & $\mathrm{B}$ & $\mathrm{C}$ \\
\hline Lactation 1 & 1.45 & 0.02913 & 0.00089 \\
Lactation 2 & 1.28 & 0.10352 & 0.00217 \\
Lactation 3+ & 1.19 & 0.14706 & 0.00329
\end{tabular}

${ }^{1}$ Values for these parameters were rounded to contain most significant figures.

Table A2. Probability distribution fit for the different parameter used in the model

\begin{tabular}{llcl}
\hline Variable $^{1}$ & Distribution & Scale & Shape \\
\hline Milking interval (h) & & & \\
CMPR $>1.74$ & Lognormal & 1.97 & 0.28 \\
CMPR 1.47-1.73 & Lognormal & 2.08 & 0.3 \\
CMPR 1.22-1.46 & Lognormal & 2.13 & 0.33 \\
CMPR $<1.22$ & Lognormal & 2.25 & 0.37 \\
DIM $^{2}$ & Gamma & 68.5 & 2.1 \\
Lactation $^{2}$ & Lognormal & 0.71 & 0.52 \\
Attachment time & Lognormal & 3.5 & 0.61 \\
Preparation time & Lognormal & 4.3 & 0.7 \\
\hline
\end{tabular}

${ }^{1} \mathrm{CMPR}=$ cow milk production rates.

${ }^{2}$ Values for these parameters were rounded to one decimal place.

Table A3. Fitted parameters of the double sigmoid curve

\begin{tabular}{lcccc}
\hline Parameter $^{1}$ & Mean & SD & Minimum & Maximum \\
\hline $\mathrm{K}(\mathrm{kg} / \mathrm{min})$ & 1.2 & 0.5 & 0.3 & 4.3 \\
$\mathrm{~B}(\mathrm{~s})$ & 27 & 20 & 9 & 250 \\
$\mathrm{~B} 2(\mathrm{~s})$ & 230 & 104 & 35 & 614 \\
$\mathrm{R}(\mathrm{kg} / \mathrm{min})$ & 0.1 & 0.03 & 0.02 & 0.3 \\
$\mathrm{R} 2(\mathrm{~kg} / \mathrm{min})$ & -0.13 & 0.04 & -0.3 & -0.01
\end{tabular}

${ }^{1} \mathrm{~K}=$ maximum milk flowrate $(\mathrm{kg} / \mathrm{min}) ; \mathrm{B}=$ time of the milking process $(\mathrm{s})$ when the milk flowrate is half its maximum milk flowrate when milk flowrate is increasing during milking; B2 = time of the milking process (s) when the milk flowrate is half its maximum milk flowrate when milk flowrate is decreasing during milking; $\mathrm{R}_{\mathrm{m}}=$ rate of increase of the milk flowrate $(\mathrm{kg} / \mathrm{min}) ; \mathrm{R} 2=$ rate of decrease of the milk flowrate. 